\title{
Functioning of the Kabardian language in diaspora
}

\section{[Особенности Функционирования Кабардино-Черкесского Языка в Условиях Диаспоры]}

\author{
Marita M. Abazova - Zaudin G. Hutezhev - Vyacheslav H. Unatlokov
}

DOI: 10.18355/XL.2018.11.03.09

\begin{abstract}
The main form of the Kabardian language in the diaspora is described in the paper, linguistic features of its functioning within a historical retrospective are revealed. The spoken language used in the Circassian diaspora has been significantly changed due to migration (the 1960s of the 19th century) and external and internal factors as well. It resulted in changes in language and social and cultural communicative practices in the Circassians abroad justifying that we can speak about modern forms of the Adyghe (Circassian) language in the diaspora. The article contains the conclusion that currently, the Kabardian language in the diaspora functions as an areal language, but with the main features of the parent language. The article is believed to be useful to researchers interested in studying of the Adyghe languages both in the historical homeland and abroad.

Key words: Circassian (Adyghe) diaspora, Kabardian language, areal language, local dialect, a form of language existence
\end{abstract}

\begin{abstract}
Аннотация
В статье раскрыта основная форма существования кабардино-черкесского языка в условиях диаспоры, выявлены лингвистические особенности его функционирования в исторической ретроспективе. Отмечено, что миграционные процессы (60-е гг. XIX в.), а также внешние и внутренние факторы повлекли за собой значительную трансформацию речи черкесской диаспоры. Установлено, что в результате этого языковые и социокультурные коммуникативные практики у черкесов за рубежом изменились, что дает основание говорить о современных формах существования адыгского (черкесского) языка в диаспоре. В статье делается вывод, что в настоящее время кабардино-черкесский язык в диаспоре функционирует как ареальный язык, но с сохранением основных черт праязыка. Материалы статьи могут быть полезными для исследователей, интересующихся изучением адыгских языков, как на исторической родине, так и за рубежом.
\end{abstract}

Ключевые слова: Черкесская (адыгская) диаспора, кабардино-черкесский язык, ареальный язык, территориальный диалект, форма существования языка

\section{Введение}

Актуальность исследуемой проблемы обусловлена необходимостью выявления степени и глубины лексических и фонетических изменений в речи черкесской (адыгской) диаспоры за рубежом и форм взаимодействия различных языковых систем (например, абхазо-адыгской и тюркской). В теоретическом плане исследование данной проблемы имеет важное значение для понимания особенностей адаптации черкесов к языковой и социокультурной системам стран проживания. В связи с этим, данная статья направлена на выявление особенности функционирования кабардино-черкесского языка в условиях диаспоры. Цель статьи состоит в изучении речи черкесов, проживающих за пределами исторической родины, и определении форм существования кабардино-черкесского языка в иноязычной среде. Методика и методология 
исследования основываются на комплексном подходе к изучению, систематизации и анализу полевых материалов, доступных фоноархивов и научных трудов, в которых затрагивались те или иные аспекты изучения черкесов за рубежом.

Все адыги независимо от места проживания сохраняют общее самоназвание «адыгэ», которое свидетельствует о единстве этноса по генетическим, языковым и этнокультурным показателям. Адыги (черкесы), проживающие в течение более полутора веков за рубежом (Турция, Иордания, Израиль, Египет и др.), испытывают перманентное влияние со стороны инокультурного информационного поля. За пределами исторической родины происходит активное освоение представителями диаспоры языка и элементов культуры аборигенов. Компактное проживание малых народностей в иноэтничной среде в течение длительного времени приводит к трансформации языковых систем. В рамках общей теории языка исследование поставленной проблемы позволяет охарактеризовать ряд изменений в речи адыгской (черкесской) диаспоры за рубежом, а также выявить формы существования языка в условиях диаспоры и особенности взаимодействия различных языковых систем. Кроме того, сравнительно-историческая характеристика исследуемого языка и современного кабардино-черкесского литературного языка выступает своеобразным индикатором, дающим возможность по-новому осветить ряд малоизученных аспектов трансформации адыгского этнического социума и определить формы существования кабардино-черкесского литературного языка вне исторической родины. В теоретическом плане это позволяет охарактеризовать основные направления межъязыковой коммуникации черкесской диаспоры и коренного населения стран проживания, определить некоторые закономерности изменения речи переселившегося на новое место жительства этноса под влиянием эндогенных и экзогенных факторов.

Для более глубокого понимания современных форм существования кабардиночеркесского языка в условиях диаспоры важное значение представляет изучение особенностей его трансформации в исторической ретроспективе. Это дает возможность выявить основные изменения в их речи на всех уровнях (в звуковом строе, лексике, морфологии, синтаксисе, словообразовании).

\section{Методы исследования}

Методами исследования являются широкий круг источников, которые можно дифференцировать по видовой принадлежности на следующие группы:

- аудио-видеозаписи бесед с респондентами различных половозрастных групп, собранные в ходе нескольких экспедиций в Турции, а также при опросе адыговрепатриантов из этой страны, проживающих в России;

- фонотеки и фоноархивы научных учреждений, в которых хранятся записи речи представителей диаспоры, собранные в разное время. Например, в фотоархиве Института гуманитарных исследований Кабардино-Балкарского научного центра Российской академии наук (г. Нальчик, Россия) содержатся собранные в 1994 г. в Турции, Иордании и Сирии аудиозаписи разговоров с представителями черкесской диаспоры.

- данные речи представителей черкесской диаспоры зарубежном, использованные различными кавказоведами в качестве эмпирического материала в научных работах (Bizhoev, 2000; Dumézil, 1965, 1975; Helig, 1993; Kumakhov, 1981).

Эти материалы дают возможность выявить формы существования кабардиночеркесского языка в условиях диаспоры и определить степень его изменения в иноэтничной языковой среде.

XLinguae, Volume 11, Issue 3, June 2018, ISSN 1337-8384, eISSN 2453-711X 
В работе были использованы описательный, сопоставительный, сравнительноисторический, контекстуальный и этнолингвистический методы и метод синхронного лингвистического описания материала. Описательный метод применялся для сбора и систематизации материалов по теме исследования. Сопоставительный метод использовался для привлечения материала из языков различных субэтнических групп адыгов. Сравнительно-исторический - для восстановления некоторых фактов истории адыгской (черкесской) диаспоры за рубежом. Применение контекстуального метода в данном исследовании осуществлялось для определения степени трансформации речи черкесской диаспоры под влиянием иноязычного окружения. Этнолингвистический метод использовался для характеристики конкретных говоров и диалектов кабардиночеркесского языка. Метод синхронного лингвистического описания материала применялся при выявлении и описании заимствованной лексики в речи черкесской (адыгской) диаспоры за рубежом. Совокупность используемых методов лингвистического исследования позволило выявить основные формы существования кабардино-черкесского языка в условиях диаспоры и определить основные факторы его изменения под влиянием внешних и внутренних факторов.

\section{Результаты и их обсуждение}

В настоящее время большая часть черкесов проживает за пределами России. Поэтому черкесская диаспора по численности является одной из самых крупных в мире. Переселившись в Османскую империю во второй половине ХХ в., черкесские мигранты составили основу для формирования многомиллионной черкесской диаспоры, которая в настоящее время расселяется в Турции, Иордании, Израиле, США, Германии, Нидерландах и других странах. При этом представители диаспоры в разных странах продолжают сохранять язык и основные элементы этнической культуры.

В языкознании выделяют несколько форм существования языка. К ним относятся: диалекты (территориальные), просторечие (речь неграмотных или недостаточно грамотных слоев населения), жаргоны (речь отдельных профессиональных, социальных групп с целью языкового обособления) и литературный язык (Public language and its versions, 2016).

Исследуя речь черкесов за рубежом, можно выявить территориально ограниченные формы существования литературного кабардино-черкесского языка, в которых до сих пор сохраняются архаичные и естественные элементы языка. В общем смысле речь черкесской диаспоры за рубежом можно отнести к ареальным формам существования языка, которые в свою очередь можно дифференцировать на устную (в большинстве случаев) и письменную (написанную латиницей). Основным критерием, по которому речь всей диаспоры относится к этой форме, является то, что по сей день в диаспоре удалось сохранить основные черты языка-источника, но в то же время произошли изменения во всех уровнях языковой системы.

Постоянные контакты черкесов с представителями иноязычного населения стран проживания привели к появлению в их речи интеркаляций, например, yani (уа'ni) вместо nehg"uehshchIu zhypIeme «то есть» (IGI KBNTs RAS, 1074, 1072, 1076, 1078); tabi (tabi) вместо dauikI, shech hemyl"u «конечно» (IGI KBNTs RAS, 1069, 1072, 1079), dah'a (daha) вместо idzhyri «еще» (IGI KBNTs RAS, 1067, 1068, 1073), aе-ае вместо реjş-реjş «верно-верно» (РMA, 0014), Syria вместо Sirie (IGI KBNTs RAS, 1067, 1065, 1068) «Сирия», которые можно заменить эквивалентами из литературного кабардино-черкесского языка. В речи молодежи в большей степени наблюдается увеличение удельной формы лексических вкраплений. Это свидетельствует о том, что молодое поколение представителей черкесской диаспоры стремительно переходят на 
государственный язык страны проживания или на тот язык, который доминирует в конкретной местности. Складывается ситуация, когда «старшее поколение еще владеет черкесским языком, а среди молодежи он, как фактор выражения этнической идентичности, стремительно теряет свои позиции» (Abazova, 2014). Кроме этого ситуация осложняется еще и тем, что в этих условиях дети подвергаются ассимиляции и забывают родную речь, проводя значительное время в окружении иноязычных сверстников.

Анализ источников показывает, что речь черкесской диаспоры за рубежом претерпевает изменения также и на других уровнях языка: в звуковом строе, лексике, морфологии, синтаксисе, словообразовании. Так например, фонетические изменения: Psori deh diIehs, deh zyri dyhuehnyk"uehIym. вместо dilehshch «У нас все есть, мы ни в чем не нуждаемся» (PMA, 0015), Seh syadigehs zhyzoIeh. вместо adygeh «Я говорю, что я адыг, черкес» (РМА, 0014); лексико-семантические изменения: unehcIeh в значении «род» вместо l"ehpk" (IGI KBNTs RAS, 1074; PMA, 001), in в значении «старший» вместо nehkh"yzh' (PMA, 0010) и т.д.; словообразование: g"ueshx вместо sag"yz «жвачка» (PMA, 0015), образуется от zh'ehg"uashkhen - то есть «жевать»; l"ehpaguebze вместо tyrkubze (IGI KBNTs RAS, 1074, 1079), эта лексема образуется сочетанием этнонима «l"ehpagueh» (некоторые черкесы, проживающие в Турции так называют турков) и «bzeh»- язык и др.

В ходе исследования выявлены основные факторы трансформации речевых оборотов черкесов, проживающих за рубежом и появления новых форм кабардино-черкесского в условиях диаспоры. В качестве основного фактора определяется массовая миграция черкесов за рубеж, которая началась на завершающем этапе Кавказской войны в 60-е гг. XIX в, а также дисперсный характер проживания. Во второй половине XIX в. Кавказ покинуло от 500 тыс. до 1,7 млн человек (Berzedzh, 1996). С этого времени язык менялся в условиях постоянных контактов черкесов с представителями тюркоязычного и арабоязычного населения Османской империи, ее этнической политики, распадом в начале $\mathrm{XX}$ в.

На основании анализа полевых материалов и аудиозаписей, доступных фоноархивов выявлена, что адыгский (черкесский) язык за пределами исторической родины функционирует как ареальный, то есть территориально ограниченная. Установлено, до сих пор сохраняются архаичные лексические единицы (например, числительные 40 mIowIumI, то есть два по двадиать, вместо плІьщц ; 50 щэныкъуэ, то есть половина ста, вместо тхущІ (РМА, 0010; IGI KBNTs RAS, 1064, 1079). Со временем в результате постоянных контактов представителей диаспоры с местными жителями в речи черкесов появились интеркаляций, туркизмы, арабизмы, которые можно заменить эквивалентами из литературного кабардино-черкесского языка. Выявлена специфика изменений речи диаспоры и на других уровнях языка (в звуковом строе, лексике, морфологии, синтаксисе, словообразовании). Определены не только механизмы сохранения кабардино-черкесского языка в условиях диаспоры, но и дальнейшие перспективы существования. Охарактеризованы новые формы существования кабардино-черкесского языка в условиях массового возвращения черкесов на историческую родину (репатриация) в настоящее время.

Все вышеперечисленные изменения в речи адыгской (черкесской) диаспоры позволяют сделать вывод, что кабардино-черкесский язык существует в диаспоре как ареальный. Это определяется диглоссией - отсутствием письменности, (ведь с помощью кириллицы или латиницы передать и написать слова на кабардино-черкесском языке невозможно, так как некоторые звуки состоят из 2-х и более букв, например, буква «кхъу», где 4 звука обозначают 1 букву), тесной связи с основной массой черкесов на исторической родине и

XLinguae, Volume 11, Issue 3, June 2018, ISSN 1337-8384, eISSN 2453-711X 
многоязычной средой в стане проживания. Образование ареального языка схематический: АБХАЗО-АДЫГСКИЕ ЯЗЫКИ (включая все говоры и диалекты) + ТУРЕЦКИЙ + АРАБСКИЙ $\rightarrow$ АРЕАЛЬНЫЙ ЯЗЫК.

Изучение форм существования языка в диаспоре позволяет определить не только механизмы его сохранения, но и дальнейшие перспективы существования. Следует отметить, что в разное время были выработаны различные механизмы его сохранения: создание курсов, проектов для обучения черкесскому языку, учреждения общественных организации, издание газет и т.д. Кроме того, как считает Б. Ч. Бижоев, языковая ситуация в диаспоре особенно усугубилась на рубеже XX - XXI вв. в связи со стремительной урбанизацией в странах проживание черкесской диаспоры (Bizhoev, 2005). Он также полагает, что «самой надежной, а может, и единственной мерой для сохранения языка, для избежания ассимиляции, является возвращение на историческую родину (Bizhoev, 2000). С этим можно согласиться, так как «обязательными компонентами (любой) языковой политики должны быть меры, направленные на сохранения языков как культурной ценности, на защиту культурной национальной самобытности народа» (Bashiyeva, Ulakov, Hamdokhova, 2016).

Однако в современных условиях можно выделить и другие механизмы сохранения языка. Так, в постиндустриальном обществе с появлением и развитием новых информационных технологий некоторые формы существования языка перемещаются в виртуальное пространство (интернет). Оно «является не только важным фактором сохранения единого этнокультурного пространства, но и воссоединения разделенных в историческом прошлом народов» (Kulturbayeva, 2007). С появлением различных соцсетей (Facebook, Skype, ВКонтакте и т.д.) у черкесской молодежи, проживающей за рубежом, появилось больше возможностей пообщаться с соотечественниками. Также в сети интернет есть обучающие курсы (например, «TелеStudio» (уроки кабардинского и балкарского языков) (Telestudio, 2016), Северо-Кавказские новости (North Caucasian news, 2016) и др.), которые дают возможность значительно повысить уровень владения кабардино-черкесским литературным языком.

Помимо прочего, важным экстралингвистическим фактором, влияющим на языковую ситуацию не только за рубежом, но и на исторической родине являются: семья, детский сад, школа и т.д., которые должны участвовать в языковом строительстве. Существует множество механизмов сохранения языка, из которых наиболее эффективными является их юридическая (принять закон в странах проживания черкесов, разрешающий официально изучать родной язык), экономическая, социальная задача. Среди них: налаживание выпусков учебников и учебных пособий на родных языках, социальные программы, направленные на сохранение норм языка, поведенческих норм, культуры вне исторической родины.

Следует особо отметить, что в настоящее время стали появляться новые формы существования кабардино-черкесского языка в условиях массового возвращения черкесов на историческую родину (репатриация). Например, на данный момент в Кабардино-Балкарской Республике проживает большое количество черкесских репатриантов, среди которых в основном выходцы из Турции и Сирии. В различных высших учебных заведениях республики обучаются более 500 черкесов из разных стран. Проживая на исторической родине, по рассказам самих студентов, они лучше осваивают родной и русский языки, учат алфавит, становятся билингвами, то есть кроме тюркизмов и арабизмов представители диаспоры начинают употреблять еще и русизмы. Полагаем, что такая ситуация уже помимо появления новых форм существования кабардино-черкесского языка, дает дополнительный импульс к его сохранению. Межъязыковая 
коммуникация репатриантов и автохтонов способствуют формированию более устойчивых форм существования языка как для одной, так и для другой стороны.

\section{Выводы}

Адыгский (черкесский) язык существует в диаспоре, но как ареальный язык, которая определяется диглоссией, а именно отсутствием тесной связи с основной массой адыг, проживающих в России, и многоязычной средой. Они создали свой язык (речь), но с сохранением основных черт языка-источника. Не имея письменности и литературного языка, представители черкесской диаспоры за рубежом на сегодняшний момент смогли сохранить свой язык (речь), на котором они общаются между собой и передают из поколения в поколения традиций, обычай (адыгэ хабзэ «адыгский этикет»), обряды, культуру и т.д. Следует отметить, что у них сохранились некоторые архаичные слова, которые утрачены на исторической родине, а также отмечается наличие в речи неологизмов, выявлено большое фразеологических единиц, некоторые из которых отсутствуют в литературном кабардино-черкесском языке. Таким образом, для сохранения кабардино-черкесского языка в диаспоре необходимо использовать максимально эффективные методы. Один из основных - передача языка подрастающему поколению.

Результаты исследования имеют важное значение для понимания специфики лингвистических и этнокультурных процессов на современном Ближнем Востоке и отчасти Кавказе, а также могут быть использованы при дальнейшем изучении межъязыковой коммуникации адыгов в целом; в научных исследованиях не только по языкознанию, но и по истории и этнографии адыгов; при подготовке лекционных курсов, учебников и учебных пособий по филологии народов Северного Кавказа.

\section{Bibliographic references}

BASHIYEVA, S.K. - ULAKOV, M.Z. - HAMDOKHOVA, Zh.M. 2016. Language situation in the Kabardino-Balkar Republic: state and problems. Nalchik: KBNTs RAS. ISBN 978-5-901497-83-8.

BERZEDZH, N. 1996. Exile of Circassians (reasons and consequences). Maykop: Republican publishing and printing merging "Adygea" of the Ministry of National Policy.

BIZHOEV, B.Ch. 2000. Language of the Circassian diaspora in Syria, Jordan, Turkey. Nalchik: "Elfa". ISBN 5-88195-425-4.

BIZHOEV, B.Ch. 2005. Kabardian language in the countries of the Middle East: social and linguistic aspect. In: Philology questions, n. 2, 15-22. ISSN 1562-1391.

DUME'ZIL, G. 1965. Documents Anatoliens sur les langues les du Caucase III. Paris: Librairie A. Maisonneuve.

DUME'ZIL, G. 1975. Le verbe oubykh: Études descriptives et comparatives. Paris: Imprimerie Nationale et Librairie C. Klincksieck.

HELIG, M. 1993. The Abadzekhsky dialect of the Circassian diaspora in Turkey, Cultural diaspora of the Caucasian people. In: Materials of the international scientific conference. Cherkessk: Karachay-Cherkess scientific research institute of history, philology and economy, pp. 358-366. ISBN 5-85183-001-8

IGI KBNTs RAS. 1065. In: Phonoarchive re:1065, No. 744 - f/4. Syria.

IGI KBNTs RAS. 1067. In: Phonoarchive re: 1067, No. $744-\mathrm{f} / 6$. Syria.

IGI KBNTs RAS. 1068. In: Phonoarchive re: 1068, No. 744 - f/7. Jordan, Syria.

IGI KBNTs RAS. 1072. In: Phonoarchive re: 1072, No. 744 - f/11. Jordan.

IGI KBNTs RAS. 1073. In: Phonoarchive re: 1073 , No. 744 - f/12. Turkey.

IGI KBNTs RAS. 1074. In: Phonoarchive re: 1074, No. 744 - f/13. Turkey.

XLinguae, Volume 11, Issue 3, June 2018, ISSN 1337-8384, eISSN 2453-711X 
IGI KBNTs RAS. 1076. In: Phonoarchive re: 1076, No. 744 - f/15. Turkey.

IGI KBNTs RAS. 1078. In: Phonoarchive re: 1078, No. $744-\mathrm{f} / 17$. Turkey.

IGI KBNTs RAS. 1079. In: Phonoarchive re: 1079, No. 744 - f/18. Turkey.

KULTURBAYEVA, L.M. 2007. Social functions of ethnocultural traditions in globalization: PhD Thesis. Nalchik.

KUMAKHOV, M.A. 1981. Comparative-historical phonetics of the Adyghe (Circassian) languages. Moscow: Science. ISBN 416-81 4602010000

NORTH CAUCASIAN NEWS. 2016. Retrieved on December 14, from sknews.ru/lang/adyg.php.

PMA AN AUDIO RECORDING. 0010. The informant - Shanibov Ersin, 52. Istanbul.

PMA AN AUDIO RECORDING. 0014. The informant - Akbay Iskhak, 30. Istanbul. PMA AN AUDIO RECORDING. 0015. The informant - Sizhazhev Syltyk, 23. Istanbul.

PUBLIC LANGUAGE AND ITS VERSIONS. 2016. Electronic resource. Retrieved on December 13, 2016, Available online: http://zdamsam.ru/a55171.html.

TELESTUDIO. 2016. Electronic resource. Retrieved on December 13, 2016, Available online: http://www.telestudio.pro/.

Words: 2811

Characters: 22608 (12,56 standard pages)

Marita M. Abazova PhD.

Institute for the Humanities Research - Affiliated Federal State Budgetary Scientific Establishment "Federal Scientific Center "Kabardino-Balkarian Scientific Center of the Russian Academy of Sciences"

18 Pushkin Str., 360000 Nalchik

Russia

marita.abazova@yandex.ru

Zaudin G. Hutezhev PhD.

Kabardino-Balkarian State University named after H. M. Berbekov

Department of Kabardian-Circassian Language and Literature

173 Chernyshevsky Str., 360004 Nalchik

Russia

zaudin-777@mail.ru

Vyacheslav H. Unatlokov PhD.

Kabardino-Balkarian State University named after H. M. Berbekov

Department of Kabardian-Circassian Language and Literature

173 Chernyshevsky Str., 360004 Nalchik

Russia

vunatlokov@mail.ru 